\title{
Cortical Blindness: A Rare but Dramatic Complication following Coronary Angiography
}

\author{
B. Gellen T.Remp T. Mayer P. Milz W.-M. Franz \\ Department of Cardiology, Klinikum Grosshadern, Ludwig Maximilians University Munich, Germany
}

Dear Sir,

Transient cortical blindness $(\mathrm{CB})$ is a rare but dramatic dye-induced complication associated with coronary angiography (only 11 cases are known). It is characterized by complete loss of visual perception with preservation of ocular motility, papillary responses and normal fundoscopic examination. $\mathrm{CB}$ is selective functional impairment of the occipital visual cortex. Symptoms of dye-induced $\mathrm{CB}$ result from extravasation of the contrast medium into the posterior circulation of the brain.

We report on a 52-year-old hypertensive patient with end-stage renal failure and a LIMA bypass graft developing blindness immediately following diagnostic coronary angiography. $400 \mathrm{ml}$ of the contrast agent iopamidol were applied. Immediately following angiography, the patient complained of visual impairment which progressed to complete blindness within $30 \mathrm{~min}$. Neurologic examinations including fundoscopy and pupillary responses were normal. A CT of the brain performed $3 \mathrm{~h}$ after angiography revealed extensive contrast extravasation into the posterior circulation (fig. 1A, B). The following day, the patient's vision improved gradually. A second CT scan $30 \mathrm{~h}$ after angiography showed only residual enhancement (fig. 1E, F). Three days after catheterization, the patient's vision returned to normal.
Currently used non-ionic contrast media have an osmolality which is about twice that of plasma. The intravascular injection of hyperosmolar contrast agents causes a transient increase in blood osmolality, leading to a temporary breakdown of the blood-brain barrier in some patients. Subsequent injections may result in extravasation of the dye into the subarachnoid space and brain tissue resulting in neurological deficits due to direct neurotoxic effects of the contrast medium. The exact mechanism of the neurotoxicity is still unclear. Factors that may contribute to the disruption of the blood-brain barrier are decreased clearance of the substance in patients with impaired renal function and pre-existing endothelial dysfunction in patients with cardiovascular risk factors.

CB after coronary angiography was reported following both high-osmolality ionic $[1,2]$ and modern low-osmolality non-ionic contrast agents [3-7]. The incidence and duration of blindness seem to be unrelated to the dose of contrast medium applied. The majority of the patients had previously been exposed to dye without developing any neurological symptoms. Four patients with a history of $\mathrm{CB}$ were re-exposed to contrast medium within a few months $[4,5]$. They were pretreated with corticosteroids, and a relatively small amount of contrast agent was given (80-180 ml). In 3 cases [5], reexposure did not lead to recurrence of CB. In contrast, 1 patient [4] developed $\mathrm{CB}$ again. Thus, patients with $\mathrm{CB}$ following previous contrast medium exposure may be at increased risk of developing $\mathrm{CB}$ at re-exposure. In the future, if re-exposure to a contrast medium in patients with previous $\mathrm{CB}$ is inevitable, pre-treatment with corticosteroids should be performed and the smallest possible amount of contrast medium should be given.

Five of the 12 cases observed to date (table 1) had a LIMA bypass graft. As the LIMA graft and the left vertebral artery arise in close proximity to the subclavian artery, it is possible that during repeated attempts at selective cannulation of the LIMA graft, a considerable amount of contrast medium passed into the left vertebral artery. If dye applied at the beginning of the procedure has already led to disruption of the blood-brain barrier, selective injection of the vertebral artery may result in extravasation of a large amount of contrast medium into the posterior circulation. Thus, in patients with a LIMA bypass graft, we suggest to perform injection of the LIMA graft at the beginning of the procedure and to avoid selective vertebral artery injection if possible.

\begin{tabular}{ll}
\hline KARGER & ( ) 2003 S. Karger AG, Basel \\
0008-6312/03/0991-0057\$19.50/0 \\
$\begin{array}{l}\text { Fax +4161306 1234 } \\
\begin{array}{l}\text { E-Mail karger@karger.ch } \\
\text { www.karger.com }\end{array}\end{array}$ & $\begin{array}{l}\text { Accessible online at: } \\
\text { www.karger.com/crd }\end{array}$
\end{tabular}

Priv.-Doz. Dr. Wolfgang-M. Franz, Department of Cardiology Klinikum Grosshadern, Ludwig Maximilians University Munich Marchioninistrasse 15, D-81377 Munich (Germany)

Tel. +49 897095 3094, Fax +49 8970956094

E-Mailwfranz@helios.med.uni-muenchen.de 
Fig. 1. A, B CT scan $4 \mathrm{~h}$ after catheterization: contrast extravasation into the subarachnoid space and enhancement of the cerebellum, the occipital cortex, the posterior part of the temporal gyri and the left thalamus. C, D MRI scan $5 \mathrm{~h}$ after catheterization: in the diffusion weighted images, slight signal increase in the cerebellar hemispheres. Normal signal in the $\mathrm{T}_{2}$-weighted images. E, F CT scan $30 \mathrm{~h}$ after catheterization: still enhancement of both occipital and dorsal temporal lobes. Contrast medium remnant in the local sulci.

In future cases of visual impairment following heart catheterization, a CT of the brain without additional contrast medium should be performed immediately. If no signs of acute thromboembolism are present and subarachnoidal extravasation of the contrast medium could be documented, the diagnosis of dye-induced $\mathrm{CB}$ can be made.

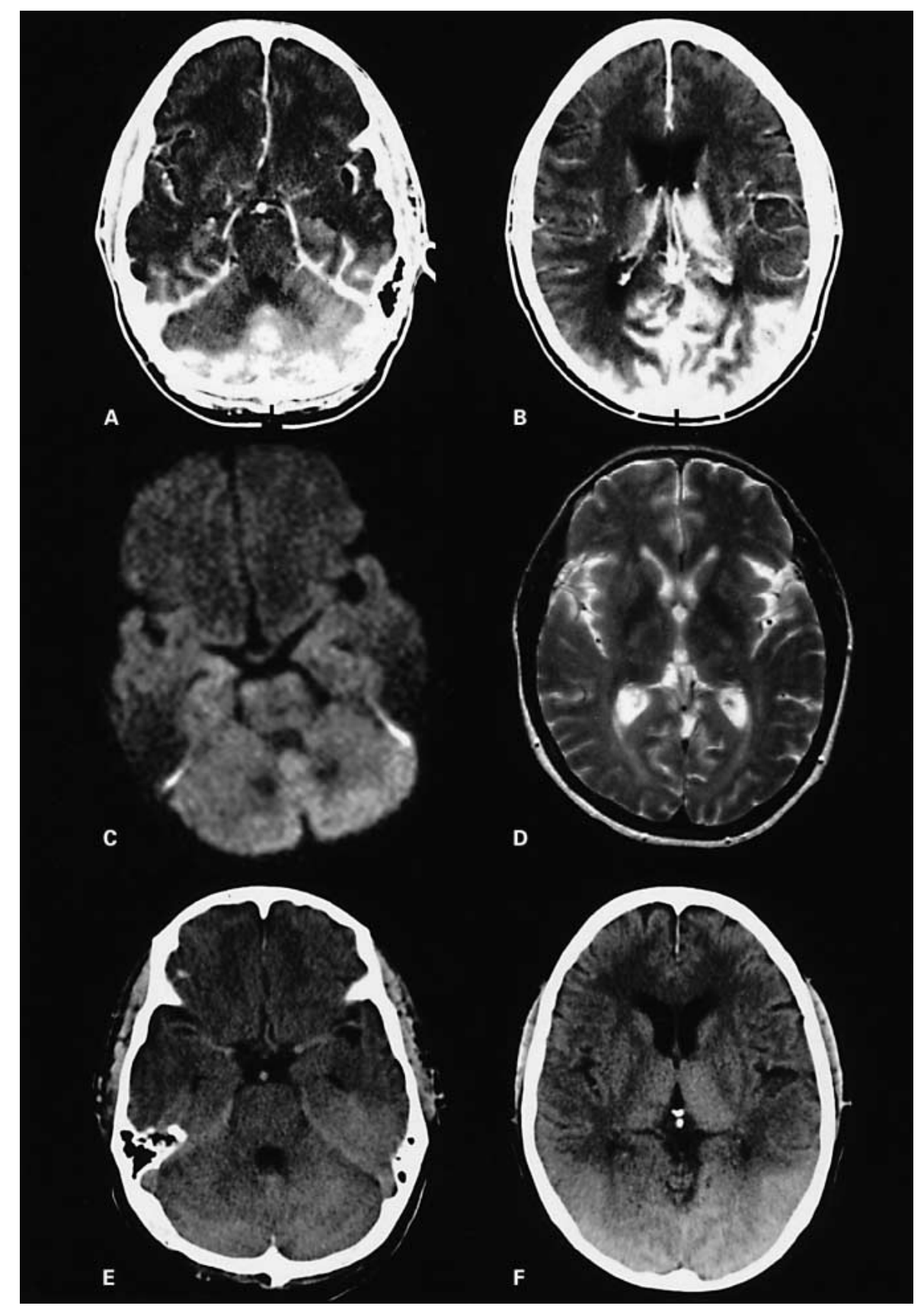

Thus the prognosis of $\mathrm{CB}$ is excellent, the most important step is to reassure the patient that symptoms will resolve completely within a few days. No therapy has been proven to be effective, therefore no additional steps should be taken.

In future studies on dye-induced $\mathrm{CB}$, all pre-existing cardiovascular risk factors and the actual renal function of the patient should be assessed in order to better identify possible risk groups and to develop prophylactic and therapeutic strategies. The excellent prognosis of CB justifies re-exposure under the above-mentioned precautions. 
Table 1. Summary of all known cases with CB following coronary angiography

\begin{tabular}{rcclccccccc}
\hline & Sex & Age & $\begin{array}{l}\text { Contrast } \\
\text { medium }\end{array}$ & $\begin{array}{l}\text { Osmolality } \\
\text { mosm/kg }\end{array}$ & $\begin{array}{l}\text { Volume } \\
\text { injected } \\
\mathrm{cm}^{3}\end{array}$ & $\begin{array}{l}\text { Duration } \\
\text { of CB }\end{array}$ & $\begin{array}{l}\text { Previous } \\
\text { exposure }\end{array}$ & $\begin{array}{l}\text { LIMA } \\
\text { bypass } \\
\text { graft }\end{array}$ & $\begin{array}{l}\text { Impaired } \\
\text { renal } \\
\text { function }\end{array}$ & $\begin{array}{l}\text { Arterial } \\
\text { hyper- } \\
\text { tension }\end{array}$ \\
\hline 1 & W & 52 & Diatrizoate & 2,100 & NI & $18 \mathrm{~h}$ & no & no & NI & yes \\
2 & W & 57 & Ioxaglate & 577 & 200 & $48 \mathrm{~h}$ & yes & yes & no & yes \\
3 & M & 55 & Diatrizoate & 2,100 & 228 & $24 \mathrm{~h}$ & yes & no & NI & yes \\
4 & M & 61 & Diatrizoate & 2,100 & 210 & $36 \mathrm{~h}$ & yes & yes & NI & yes \\
5 & M & 44 & Diatrizoate & 2,100 & 112 & $12 \mathrm{~h}$ & no & no & NI & yes \\
6 & M & 59 & Ioversol & 790 & 220 & $12 \mathrm{~h}$ & yes & no & NI & NI \\
7 & M & 45 & Ioversol & 790 & 167 & $24 \mathrm{~h}$ & yes & no & NI & NI \\
8 & M & 68 & Ioversol & 790 & 262 & $15 \mathrm{~min}$ & no & no & NI & NI \\
9 & M & 62 & Iopamidol & 774 & 270 & $72 \mathrm{~h}$ & yes & yes & NI & yes \\
10 & M & 55 & Iomeprol & 610 & 280 & $120 \mathrm{~h}$ & yes & yes & NI & no \\
11 & M & 53 & Ioversol & 790 & 100 & $12 \mathrm{~h}$ & no & no & NI & NI \\
12 & M & 52 & Iopamidol & 774 & 400 & $72 \mathrm{~h}$ & yes & yes & yes & yes \\
\hline
\end{tabular}

$\mathrm{NI}=$ Not indicated

\section{References}

1 Fischer-Williams M, Gottschalk PG, Browell JN: Transient cortical blindness: An unusual complication of coronary angiography. Neurology 1970;20:353-355.

2 Kinn RM, Breisblatt WM: Cortical blindness after coronary angiography: A rare but reversible complication. Cathet Cardiovasc Diagn 1991;22:177-179.
3 Kwok BWK, Lim TT: Cortical blindness following coronary angiography. Singapore Med J 2000;41:604-605.

4 Henzlova MJ, Coghlan HC, Dean LS, Taylor JL: Cortical blindness after left internal mammary artery to left anterior descending coronary artery graft angiography. Cathet Cardiovasc Diagn 1988;15:37-39.

5 Rama BN, Pagano TV, DelCore M, Knobel KR, Lee J: Cortical blindness after cardiac catheterization: Effect of rechallenge with dye. Cathet Cardiovasc Diagn 1993;28:149-151.
6 Parry R, Rees JR, Wilde P: Transient cortical blindness after coronary angiography. Br Heart J 1993; 70:563-564.

7 Sticherling C, Berkefeld J, Auch-Schwelk W, Lanfermann H: Transient bilateral cortical blindness after coronary angiography (letter). Lancet 1998;351:570.

\section{Announcement}

\section{1st Review Course in Clinical Cardiology in Zurich}

Clinical Cardiology and Echocardiography Update

Hotel Marriott, Zurich, Switzerland, April 25-26, 2003

Information:

Noémie Sandoz

Eggenwilerstrasse 13a

CH-5620 Bremgarten

Tel. +415664828 00, Fax +41566482801

E-Mailinfo@contenter.ch 